\title{
INDUSTRIAL POLLUTION PREVENTION PROGRAMS IN SELECTED DEVELOPING ASIAN COUNTRIES
}

\author{
Shen-yann Chiu, Ph.D. \\ Environmental Assessment Division \\ Argonne National Laboratory \\ Argonne, Illinois 60439 U.S.A. \\ and \\ Program on Environment \\ East-West Center \\ Honolulu, Hawaii 96848 U.S.A.

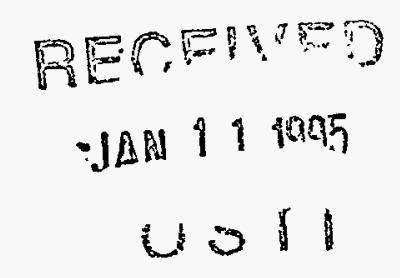

\begin{abstract}
This paper presents the information on current activities to promote industrial pollution prevention (P2) in five selected Asian economies including Hong Kong, Republic of Korea, the Philippines, ROC in Taiwan, and Thailand. These activities, generally initiated in the last 5 years, are classified into 6 categories: awareness promotion, education and training, information transfer, technology development an demonstration, technical assistance, and financial incentives. Although participation is voluntary, these programs are all important at the early stages of P2 promotion and should be useful in informing industries of the benefit of $\mathrm{P} 2$ and helping them identify specific $\mathrm{P} 2$ measures as viable environmental management alternatives.
\end{abstract}

Keyword: Industrial Pollution Prevention, Promotion Programs, Asian Countries

\section{INTRODUCTION}

Many developing countries in Asia and the Pacific Basin are experiencing rapid industrialization. Among the consequences are potentially serious environmental and health problems resulting from highly pollutive industries commonly found in these countries, such as chemical, electroplating, tanning, paper and pulp, and food processing. The majority of these industries are still being run with little use of environmental control. To alleviate these problems, some countries have begun to develop and enforce environmental regulations that resemble those of the developed nations decades ago -- by focusing on treating effluents and emissions after they are generated. The concept is known as "end-of-pipe (EOP)" treatment. Although EOP treatment is proven effective method of protecting the environment, it has some disadvantages. It is costly to control pollutants after they are generated; moreover, it can transfer pollutants from one medium to another, thereby resulting in no net environmental benefit.

The limitations of EOP treatment have caused environmental decision makers in many developed nations to consider alternative methods of pollution control. Because it is clearly preferable to avoid producing pollutants in the first place, rather than treating effluents prior to discharge, EOP treatment is being replaced, where practical, by a preferred method of environmental management. This concept, called "industrial waste minimization (IWM)," "pollution prevention (P2)," and more recently "cleaner 
production (CP)," now pervades environmental programs for protecting air, water, and land in many developed nations.

P2 is a method of multimedia pollution control and management that focuses on reducing the generation and discharge of pollutants (gaseous, aqueous and solid) at their source to avoid subsequent handling, treatment, and disposal. P2 encourages industry to reduce its hazardous pollutants at the source, rather than to treat and dispose of pollutants in the environment. This preferred strategy for dealing with chemical pollutants is often referred to as the "environmental management option hierarchy." This hierarchy ranks source reduction and source elimination as the highest; recycling and reuse are next, followed by treatment of effluents and emissions to reduce volume and/or toxicity. Finally, legally permitted disposal (e.g., putting waste-filled barrels in secured landfills) is the least desirable waste management technique.

Although P2 has numerous advantages, it has not attracted substantial attention from the public until recently. For example, in parts of Europe, interest in source reduction and low-waste technologies has been evolving over the last 10 to 20 years. Results of industrial firms in Germany, Sweden and the Netherlands have demonstrated benefits of P2 approaches. Many laws and social attitudes have already made the transition from EOP control to P2, and some even focus on product design and utilization optimization. In the United States it was only in the 1980s that P2 began to receive serious attention following the promulgation of the Resource Conservation and Recovery Act and Superfund Act. The results thus far have been quite positive. The success stories of 3M, Dow Chemicals, and DuPont are well known. Most industrial firms in the country have adopted P2 techniques; many of them have also established specific programs aiming to implement P2 measures over the long term.

Encouraged by the results in developed nations, many Asian developing countries have initiated activities to promote the P2 concept and encourage domestic industries to adopt P2 measures. The purpose of this paper is to present information on P2 programs in the five Asian countries including Hong Kong, Republic of Korea, the Philippines, ROC in Taiwan, and Thailand. Individual country's P2 programs are summarized in Table I and described in detail in the sections that follow.

\section{POLLUTION PREVENTION PROGRAMS}

\section{Hong Kong}

At present, the Hong Kong government has not yet formulated policies or strategies specific to promotion of cleaner production technologies. However, following completion of a government-launched consultancy study on the support to industry on environmental matters, the government recently established a working group on $\mathrm{CP}$ to look into possible actions that could facilitate and enhance the development of cleaner technologies for local industries. The working group comprises representatives from government departments, academic institutes, and private organizations.

The Hong Kong Environmental Protection Department (HKEPD) has formed a Cleaner Technology Special Interest Group (CTSIG) to serve as a focal point in HKEPD for collecting and disseminating local and overseas CP information. As one information source, CTSIG has established connection to the International Cleaner Production Information Clearinghouse set up by United Nations Environmental 
Table I. Summary of Pollution Prevention Programs in Selected Asian Countries ${ }^{2}$

\begin{tabular}{|c|c|c|c|c|c|}
\hline & Hong Kong & Korea & Philippines & ROC in Taiwan & Thailand \\
\hline Status & Active & Active & Active & Active & Active \\
\hline Established & N/A & 1992 & 1991 & 1989 & 1986 \\
\hline Legislation & N/A & N/A & N/A & $\begin{array}{c}\text { Executive } \\
\text { Order }\end{array}$ & N/A \\
\hline $\begin{array}{l}\text { P2 Annual Budget } \\
\text { (million U.S.\$, 1995) } \\
\end{array}$ & N/A & $>\$ 1$ & $\$ 2.4^{b}$ & $\$ 3.5^{\circ}$ & N/A \\
\hline Funding Source(s) & $\begin{array}{c}\text { Hong Kong } \\
\text { Gov't }\end{array}$ & $\begin{array}{c}\text { Korean } \\
\text { Gov't }\end{array}$ & $\begin{array}{l}\text { Philippine } \\
\text { Gov't, USA } \\
\end{array}$ & $\begin{array}{l}\text { ROC } \\
\text { Gov't }\end{array}$ & $\begin{array}{l}\text { Thai Gov't, UN, USA, } \\
\text { Germany, Denmark }\end{array}$ \\
\hline P2 Project/Team & $\begin{array}{l}\text { CP Working } \\
\text { Group }\end{array}$ & $\begin{array}{l}\text { HAN } \\
\text { Project }\end{array}$ & IEMP & JWRTF & $\begin{array}{l}\text { CDG-SEAPO, IEMP, } \\
\text { ASEAN/EIP, USAEP, } \\
\text { DANCED }\end{array}$ \\
\hline $\begin{array}{l}\text { Performing } \\
\text { Organizations } \\
\end{array}$ & CTSIG, HKPC & $\begin{array}{l}\text { IESE/ } \\
\text { SNU }\end{array}$ & PRC & $\begin{array}{l}\text { CTCI, } \\
\text { FTIS, ITRI } \\
\end{array}$ & $\begin{array}{l}\text { TDRI, AIT, TEI, } \\
\text { Louis Berger Int. }\end{array}$ \\
\hline \multicolumn{6}{|c|}{ Activities } \\
\hline $\begin{array}{l}\text { Awareness } \\
\text { Promotion }\end{array}$ & - & - & - & • & - \\
\hline Awards & & - & - & - & \\
\hline $\begin{array}{l}\text { Training and } \\
\text { Education }\end{array}$ & - & - & - & - & - \\
\hline $\begin{array}{l}\text { Technical Information } \\
\text { Exchange }\end{array}$ & - & - & - & - & - \\
\hline Waste Exchange & & & - & - & \\
\hline $\begin{array}{l}\text { Technology } \\
\text { Development } \\
\text { and Demonstration }\end{array}$ & - & - & & - & • \\
\hline $\begin{array}{l}\text { On-Site Technical } \\
\text { Assistance }\end{array}$ & - & & - & - & \\
\hline Financial Incentives & & - &.$c$ & • & \\
\hline
\end{tabular}

${ }^{a}$ AIT $=$ Asian Institute of Technology (Thailand); ASEAN - EIP = Association of Southeast Asian Nations - Environmental Improvement Project; CDG-SEAPO = Carl Duisberg Gesellshaft - South East Asia Program Office; CTCI = China Technical Consultants, Inc (Taiwan); CTSIG = Cleaner Technology Special Interest Group (Hong Kong); DANCED = Danish Cooperation on Environment and Development; FIIS = Foundation of Taiwan Industry Services (Taiwan); HKPC = Hong Kong Productivity Center; IEMP = Industrial Environmental Management Project (Philippines, Thailand); IESE = Institute of Environmental Sciences and Engineering (Korea); ITRI = Industrial Technology Research Institute (Taiwan); JWRTF = Joint Waste Reduction Task Force (Taiwan); N/A = not available; SNU = Seoul National University (Korea); TDRI = Thailand Development Research Institute; TEI = Thailand Environment Institute; USAEP = U.S. Asian Environmental Partnership.

${ }^{b}$ Including budget for non-CP components.

${ }^{c}$ One-year moratorium for participating firms from issuance of cease-and-desist order by the Department of Environment and Nature Resources (Philippines). 
Programme (UNEP). HKEPD also set up a waste recycling hotline, through which the community can make enquiries on the waste recycling activities in Hong Kong (Leoung, Ching and Li 1995).

The Hong Kong Productivity Center (HKPC) is an agency that provides technical support, R\&D, and training to Hong Kong's industry. One of its major activities has been to identify solutions to environmental problems for Hong Kong businesses. In some cases, this has involved on-site technical services to identify environmental problems and assist in selecting and implementing pollution control and prevention measures. Other cases have involved R\&D of special equipment to meet specific needs. Equipment that fits into very tight space restrictions has been one of the major areas of effort. The $\mathrm{HKPC}$ also conducts training courses for industrial operators on environmental control and compliance with environmental laws and regulations.

HKPC has been playing an active role in the development and promotion of cleaner technologies. Under funding support by the Hong Kong government, HKPC is undertaking R\&D studies on CP for specific industries, including studies on low-waste electroplating and electrophoretic painting technologies for surface-finishing applications, the recycling of wastewater for the electroplating industry, and a plating process for electroplating and printed circuit board (PCB) industries. Based on an assessment by HKPC, some CP technologies have been successfully implemented, for example, nickel recovery from nickel-bearing rinsing wastewater, and recovery of caustic soda from mercerizing wastewater in the textile dyeing and finishing industry (Leoung, Ching and $\mathrm{Li}$ 1995).

HKPC is also active in providing technical assistance to domestic industry on achieving environmental control and green productivity and in raising public awareness on CP. Some examples of HKPC's related activities are: (1) publishing a quarterly journal, "Green Productivity," informing the public of the importance of sound environmental management, (2) arranging a series of cleaner technology seminars, meetings, and workshops between overseas CP technology suppliers and local industries since 1993; and (3) participating in the CP technology assessment and demonstration sponsored by the Asian Productivity Organization (APO) (Leoung, Ching and Li 1995).

\section{Republic of Korea}

Actions to promote public awareness of CP in the Republic of Korea (South Korea, hereafter called Korea) started almost five years ago. In 1990, a symposium on CP was held at Seoul National University (SNU) for the first time in Korea to introduce CP concept to the Korean industry. In 1992, a CP Symposium sponsored by World Health Organization (WHO) and United Nations Development Programme (UNDP) was held at SNU. An undergraduate course in SNU's Chemical Technology Department has been developed to introduce the CP concept to students (Lee 1994).

In 1993, a study group for CP was organized, comprising representatives from industries, universities, and research institutes. The group gathers information on $\mathrm{CP}$ technologies and disseminates it to industries. Additionally, an award program sponsored by Ministry of Environment (MOE), Chosun Daily Newspaper, and Samsung Electronics Company is being planned by the study group; organizations will be selected for recognition of their outstanding achievements in CP (Lee 1994).

In 1992, the MOE, which has primary responsibility for the nation's environmental policies and their implementation, along with Ministry of Sciences and Technology, Ministry of Trade and Energy, and 
Ministry of Construction initiated a 10-year "HAN Project for Development of Environmental Technologies." Coordinated by the National Institute of Environmental Research, the HAN Project is designed to accelerate national development of environmental sciences and technologies, minimize the impact of international environmental management standards, and foster the export of Korea's environmental technologies. The total budget of the HAN Project is estimated at U.S. $\$ 300$ million over 10 years from 1992 to 2001. Comprising seven major technological development programs, the HAN Project will emphasize development of EOP treatment technologies in the first phase (1992-97), and CP technologies in the second phase (1998-2001) (Lee 1994).

Coordinated by the Institute of Environmental Sciences and Engineering of SNU, the clean production program under the HAN Project is presently the major initiative to develop and demonstrate $\mathrm{CP}$ technologies in Korea. It has a budget of U.S. $\$ 260,000$ and $\$ 330,000$ for 1992 and 1993 , respectively, and more than U.S. $\$ 1$ million for 1994. Under this program, specific source reduction and waste recycling technologies are being studied for steelmaking, dyeing, fine chemicals, crystal glass, electroplating, metal processing, food processing, and PCB manufacturing industries. $\mathrm{CP}$ technologies for each of these industries are selected, assessed, and demonstrated; depending on their technical and economical feasibilities, they are recommended for use in domestic industries (Lee 1994).

The Korean government has implemented financial assistance to industries adopting CP. If a company wants to build a new plant or modify an existing process based on $\mathrm{CP}$ technologies developed through the HAN Project, the MOE will provide a low-interest loan to help the company purchase the technologies (Lee 1994).

\section{The Philippines}

Industrial pollution in the Philippines has escalated significantly during the past decade, adversely affecting human health and environmental quality. In response, the government initiated the Industrial Environmental Management Project (IEMP) through the Department of Environment and Natural Resources (DENR). This project, funded by the United States Agency for International Development (USAID) at a total budget of U.S. $\$ 12$ million over 5 years from 1991 to 1996, consists of three major components: P2 initiatives, capability building, and policy studies (USAID 1991).

Under the P2 initiatives of IEMP, industries are provided with technical support and encouraged to change from traditional EOP treatment to the P2 approach. An environmental risk assessment was conducted at the start of the project to identify and rank industries nationwide based on their relative potential risk to health, welfare, and the environment. Target industries on a regional basis were identified for receiving technical assistance to implement P2.

The core of the P2 initiatives is pollution management appraisal (PMA), which is a plant-audit procedure that identifies financially sound opportunities for waste reduction; 150 firms will be selected for voluntary participation in PMA. To overcome resistance by firms to participate in the PMA process, IEMP provides a number of incentives: (1) free PMA consulting services; (2) seminars for senior executives that highlight $\mathrm{P} 2$ success stories in their industries and demonstrate the benefits of practicing P2 in their facilities; and (3) a 1-year moratorium for participating firms from issuance of cease-anddesist orders by DENR (Araza et al. 1995). 
1994, 89 parties received IWM awards.

As a part of an information transfer effort, numerous IWM-related technical guidance manuals, booklets, videos, posters, and journals have been published and provided free of charge to the public. Among the guidance manuals are: (1) two IWM opportunity assessment guidances prepared for general applications, and (2) industry-specific technical guidance prepared for printed-circuit-board, paper manufacturing, textile weaving and dyeing, paint manufacturing and surface coating, printing, and dyestuff industries. Two P2 periodicals, Pollution Prevention for Sustainable Development and Waste Minimization Information Exchange are also published. All these publications are prepared in Chinese to suit the needs of user communities.

Additionally, China Technical Consultants, Inc. (CTCI) has been commissioned to establish IWM databases and serve as an information clearinghouse. One database contains data of $\mathrm{P} 2$ promotion policy and strategy, IWM techniques for specific industries, and case studies. Another data system being implemented at CTCI is the human resources information database that collects data from individuals regarding their IWM experiences.

Under the on-site technical assistance programs, a number of industrial facilities are selected each year and provided with assistance in developing and implementing IWM plans. Two private nonprofit organizations, CTCI and Foundation of Taiwan Industry Service (FTIS), are commissioned by the JWRTF to provide technical assistance without charge to the firms selected for service -- most of them small- and medium-size privately owned enterprises. From 1989 to mid-1994, 93 firms received on-site technical assistance for implementing IWM measures, resulting in savings of more than U.S. \$115 million from higher energy and process efficiency and reduced EOP treatment costs.

Under the financial assistance programs, MOEA, in cooperation with banking institutions and nonprofit organizations, provides subsidies to encourage IWM and pollution control by industry. Subsidies take a variety of forms, including direct payments, grants, and low-interest loans. Priority is given to small- to mid-sized firms. Typical low-interest loans allow for $70 \%$ of ongoing commercial loan rates for a maximum of $80 \%$ of capital investment need per case. From 1991 to 1993, MOEA approved 260 low-interest loan applications totaling U.S. \$86 million for purchasing IWM and pollution control equipment. In addition to low-interest loans, the government also offers investment tax credit through corporate income-tax deductions and accelerated depreciation of pollution control and IWM equipment.

To develop suitable P2 technologies for the domestic industry, MOEA sponsored more than 55 IWM technology research projects from 1989 to 1994 . These projects, performed at a budget of approximately U.S. $\$ 500,000 / y e a r$, are funded under numerous R\&D initiatives, including "Textile Process Modification for Pollution Control," "Automation Control Technology Development," "Metal Processing Plant Automation Technology Development," and "Development of Rational Water Usage for Industrial Processes." The IWM technologies developed under these programs have been transferred for application in local industries.

Taiwan has had an industrial waste exchange program since 1987. The program is supported by MOEA and operated by the Union Chemical Laboratories of the Industrial Technology Research Institute (ITRI). The waste exchange information is listed in the bimonthly Journal Waste Minimization Information Exchange. Between 1987 and 1993, 157 waste exchanges amounting to 160,000 tons of 
waste were accomplished.

The Taiwan government is presently formulating the second 5-year IWM plan which will be implemented beginning 1996. Most of the activities under the current 5-year plan will continue. Demands from the industry on technical and financial assistance in IWM is expected to increase as enforcement of environmental regulations will tighten in 1998. Financial assistance will be provided in favor of IWMoriented projects and less for EOP control projects. Additionally, specific financial incentive programs will be designed to attract more small-scale industries to adopt IWM. A National Clean Production Center will be established at the Union Chemical Laboratories, ITRI beginning 1996 to conduct technical and policy research aimed at promoting, among other things, multimedia pollution prevention concept, sustainable development and green consumerism based on life-cycle assessments.

\section{Thailand}

Over the last 10 years, several projects have been conducted in Thailand under multilateral or bilateral assistances that are devoted entirely or partially to P2 promotion. The key donors of these projects are UNEP, United Nations Industrial Development Organization (UNIDO), German Agency for Technical Cooperation (GTZ), Danish Cooperation on Environment and Development (DANCED), and USAID through the Industrial Environmental Management Project (IEMP), ASEAN/Environmental Improvement Project (EIP), and U.S. Asian Environmental Partnership (USAEP) initiatives.

In the mid-1980s under the sponsorship of UNEP, Thailand Development Research Institute (TDRD) evaluated the feasibility of applying 13 cleaner production (CP) technologies in pulp and paper production, textile production, and metal coating and finishing industries (TDRI 1986). The study verified that, with cost-effectiveness and product marketability, Thailand is ready to accept 5 of the 13 proposed P2 technologies, and concluded that time has not yet come for a wholesale promotion of P2 technologies.

Under an ongoing GTZ-sponsored project, specific manufacturing plants are selected from industries of high pollution potential for techno-economic studies and demonstration of appropriate P2 technologies. These industries include distilleries, tanneries, palm oil, fish canning, textile dyeing, electroplating, and chicken slaughterhouses. Additional international cooperation programs designed to provide information transfer, technology transfer, and/or policy study support for promoting P2 in Thailand include the following: (1) ASEAN/EIP, funded by USAID and involving Louis Berger International and Chemstar Laboratories, to promote environmental policy and institutional development, and provide technology transfer and training (ongoing); (2) Demonstration and implementation of CP technologies and wastewater treatment in the tannery sector, funded by UNIDO and involving Department of Industrial Works (DIW) and the Tanning Organization, to introduce $\mathrm{CP}$ by designing a full-scale hair-saving demonstration unit (1995-97); (3) A program sponsored by DANCED and involving Thailand Environment Institute (TED), Federation of Thai Industries (FTI), and Energy Conservation Center of Thailand to promote $\mathrm{CP}$ in the electroplating, textile, and food industries and to serve as a CP information center (1995-97); and (4) A program involving European Union, TEI, and Regional Institute of Environment Technology (Singapore) to reduce industrial pollution in the Province of Samutprakarn, with particular emphasis on the application of CP by conducting technology demonstration studies (expected to start early 1996) (Phantumvanit and de Mesa 1995). 
Education and publicity campaigns have been active in promoting public awareness of $\mathrm{P} 2$ concept in Thailand. Numerous international cooperation projects involved universities and research institutes where researchers, students, and faculty members were given exposure to P2 information and hands-on training to the challenges posed by actual industrial pollution control and manufacturing process demands. The seminars and workshops that were organized at the completion of various technology evaluation/demonstration programs provide opportunities to raise public awareness on the importance and benefits of $\mathrm{P} 2$.

Thailand has an information clearinghouse system that provides $\mathrm{P} 2$ technical information to industries. From 1991 to 1993, UNDDO's Environment Programme commissioned a study in Thailand focusing on energy and environment information available to small and medium industries. In response to the findings and recommendations of the study, UNIDO's Industrial and Technological Information Bank (INTIB) has started to support a pilot phase of the Energy and Environment Information System (EEIS) to be maintained at Asian Institute of Technology (AIT), Bangkok. When implemented, the EEIS will serve as an information clearinghouse, delivering industrial energy and environmental (including P2) information to industries in the country. A network of about 10 to 15 secondary contact points is being developed to expand the outreach of EEIS (Phantumvanit and de Mesa 1995).

\section{SUMMARY AND DISCUSSIONS}

The bulk of P2 programs in the five selected Asian countries were generally developed in the last 5 years. These programs were established through executive order (Taiwan), bilateral and multilateral agreements (Thailand and the Philippines), general departmental authorities (Hong Kong), or executed as part of a larger project (Korea). Funding level for P2 programs vary from "not available" (Hong Kong) to millions of dollars for Korea (over U.S. $\$ 1$ million/year) and Taiwan (U.S. \$3.5 million/year). Sources of funding for P2 programs in these countries are mainly government agencies. Funding for P2 programs in Thailand and the Philippines are generally donated from foreign countries or international organizations. The funding levels for P2 program in Philippines and Thailand are uncertain as these programs are being performed as part of larger programs that include other non-P2 components.

The sponsoring agencies of $\mathrm{P} 2$ programs are in most cases the country's environmental management regulatory agency, such as Hong Kong's HKEPD and the Philippines' DENR. The P2 program in Taiwan is jointly sponsored by the EPA and MOEA, with the latter playing the leading role. The HAN Project of Korea is jointly funded by the MOE, Ministry of Sciences and Technology, Ministry of Trade and Energy, and Ministry of Construction. The bilateral or multilateral assistance programs in Thailand in many cases involved participation of government agencies such as DIW of the Ministry of Industry.

With few exceptions, the $\mathrm{P} 2$ programs are performed mostly by organizations outside of sponsoring agencies. In Taiwan, these include CTCI, FTIS, and ITRI; in Hong Kong, the HKPC; and in Thailand, the TEI, FTI, and TDRI. Academic organizations are also involved, such as NSU in Korea, and Chulalongkorn University, Prince of Songkla University, and AIT in Thailand. In several cases, particularly under bilateral assistant programs, consulting firms such as PRC and Louis Berger International in Manila, and Carl Duisberg Gesellschaft-South East Asia Program Office (CDG-SEAPO), and Louis Berger International in Bangkok are the performing organizations. 
Programs that are implemented to promote P2 are grouped into 6 categories: (1) awareness promotion, (2) training and education, (3) information transfer, (4) technology development and demonstration, (5) technical assistance, and (6) financial incentives. These programs are discussed separately below.

\section{Awareness Promotion}

Awareness promotion is the first, and also least expensive step among many different programs to encourage adoption of P2 measures in any country. Almost all countries included in this analysis have

specific programs designed to educate the industry and the general public about the concept of P2. The promotion is being done generally through distribution of booklets, journal and newspaper articles, posters, and videos. These tools are designed to define what P2 is, explain its importance, and inform individuals about sources of $\mathrm{P} 2$ information. Another form of awareness promotion is to present awards to organizations with outstanding achievements in P2. Korea, the Philippines, and Taiwan currently present such awards.

\section{Training and Education}

The P2 concept is relatively new in many developing Asian countries. Training and education are important for industry workers and government officers. Specific programs are being implemented in almost all study countries to provide education and training on P2 techniques for industry workers. These programs are generally implemented in classrooms. In certain cases, training is brought to firm managers as well as in-plant workers at their work facilities. Under the IEMP program in the Philippines, training and education of P2 is also being provided to government workers. Additionally, P2 courses are being introduced at higher education in Korea and Thailand.

\section{Information Transfer}

General information on the nature and benefits of $\mathrm{P} 2$ technologies for specific industrial sectors is necessary for user communities, particularly case examples that illustrate technical methods and economic benefits. This type of information, commonly found in P2 guidance manuals, fact sheets, and computer databases, is available from international organizations such as UNEP and certain developed countries such as the United States, Germany, and the Netherlands, and is being made available to many developing countries. In Taiwan, guidance manuals and fact sheets have been developed that are tailored to its language and cultural conditions.

Industrial waste exchange programs are another form of information transfer. The approach of waste exchange is to match the generators of waste with potential users or buyers of the same waste through listing of waste in newsletters, magazines, and/or electronic mail. Industrial waste exchange programs in the Philippines and Taiwan appear to work quite well, contributing to waste reduction and environmental protection.

\section{Technology Development and Demonstration}

Substantial attention has been given in many Asian countries to develop detailed case studies illustrating which P2 technologies suit domestic conditions and how P2 projects have been successfully 
implemented in the country. Most of these projects emphasize testing imported CP technologies at the domestic firms. In some cases, research and development of special equipment are performed to meet specific needs. For example, equipment that fits into very tight space restrictions has been one of the major areas of development efforts in Hong Kong. Development and demonstration studies generally also include financial information on costs and benefits of projects. Table II shows industries that have local case studies of $\mathrm{P} 2$ performed.

Table II. Industrial Sectors that have Cleaner Technologies Tested, Demonstrated, or Applied

\begin{tabular}{|l|l||}
\hline \multicolumn{1}{|c|}{ Country } & \multicolumn{1}{|c|}{ Industry } \\
\hline \hline Hong Kong & Electroplating, Surface Finishing, Printed Circuit Board, Textile \\
\hline Korea & $\begin{array}{l}\text { Fine Chemicals, Textile Dyeing, Steel, Glass, Electroplating, Metal Processing, Food Processing, } \\
\text { Printed Circuit Board }\end{array}$ \\
\hline Philippines & $\begin{array}{l}\text { Sugar Milling, Pulp and Paper, Vegetable and Animal Oil Processing, Tanneries and Leather, Food } \\
\text { and Beverage, Fish Canning, Industrial Chemicals, Pig and Poultry Farming, Meat Processing, } \\
\text { Cement, Metals, Mining, Wood, Electroplating }\end{array}$ \\
\hline Taiwan & $\begin{array}{l}\text { Printed Circuit Board, Pesticides, Leather, Paper, Textile Weaving, Textile Dyeing, Electroplating, } \\
\text { Brewery, Pharmaceutical, Chemical, Seafood, Food Processing, Rubber/Plastics, Painting and Paint } \\
\text { Manufacturing, Electronics, Pottery, Defense }\end{array}$ \\
\hline Thailand & Pulp and Paper, Textile, Metal Coating, Electroplating, Food Processing, Tanneries and Leather \\
\hline
\end{tabular}

\section{Technical Assistance}

Technical assistance is being provided, especially to small and medium firms, to identify costeffective P2 opportunities. The assistance generally involves on-site services to collect data on the sources, amounts and composition of waste (or pollutant) and to provide information on available P2 options. When the P2 opportunities involve extensive projects such as changing raw material or modifying unit processes, technical assistance also provides a feasibility study for a company. On-site technical assistance services are being provided in Hong Kong, the Philippines, and Taiwan. In the past several years, 93 and 80 companies in Taiwan and the Philippines, respectively, have received such services to identify and implement P2 options.

\section{Financial Incentives}

Under the financial incentive programs, government agencies in Hong Kong, the Philippines and Taiwan provide free on-site technical assistance services to industries implementing P2 programs. Taiwan and Korea provide low-interest loans for implementing P2 and EOP projects. Additional financial incentives are also provided in Taiwan that include grants, investment tax credit, and accelerated depreciation of equipment. In the Philippines, a different incentive program is being implemented. All firms volunteered to participate in IEMP's PMA program are allowed for a one-year moratorium for issuance of cease-and-desist orders by DENR. This directly encourages adoption of P2 measures by the 
participating firms.

\section{ACKNOWLEDGMENTS}

This report was prepared as an account of work sponsored by an agency of the United States Government. Neither the United States Government nor any agency thereof, nor any of their employees, makes any warranty, express or implied, or assumes any legal liability or responsibility for the accuracy, completeness, or usefulness of any information, apparatus, product, or process disclosed, or represents that its use would not infringe privately owned rights. Reference herein to any specific commercial product, process, or service by trade name, trademark, manufacturer, or otherwise does not necessarily constitute or imply its endorsement, recommendation, or favoring by the United States Government or any agency thereof. The views and opinions of authors expressed herein do not necessarily state or reflect those of the United States Government or any agency thereof.

The work at Argonne National Laboratory was approved by the U.S. Department of Energy, Office of Assistant Secretary for International Affairs and Energy Emergency, under contract W-31-109-Eng-38. The views expressed here are that of the author's and not necessarily those of the Argonne National Laboratory or East-West Center.

\section{REFERENCES}

Araza, D. M., Jr., Cepeda, M.L., David, M.V., and Wadsworth, D.L., (1995), Pollution Management Appraisals: The Philippine Experience in Waste Minimization, paper presented at the Pacific Basin Conference on Hazardous Waste, Edmonton, Alberta, Canada, May 7-12.

Chen, W.-H., Cheng, C.-T., Huang, J.H., and Lin, C.-S., (1995), Five-Year Waste Minimization Accomplishment in Taiwan, paper presented at the Pacific Basin Conference on Hazardous Waste, Edmonton, Alberta, Canada, May 7-12.

Favila, G., (1994), A New Industrial Waste Exchange Program in the Philippines, UNEP Industry and Environment, Vol 17, No. 2, April-June.

Lee, C. H., (1994), A Case Study Related to Cleaner Production with Membrane Technology in Korea: Socio-Economic And Technical Points of View, paper presented at Seminar/Workshop: the Role of Membrane Technology in Cleaner Production, UNESCO Centre in University of New South Wales, Australia, Nov. 1-2.

Leoung Y. R., Ching, M.E., and Li, P.C., (1995), Development of Waste Minimization Technologies for Electroplating Industry in Hong Kong, paper presented at the Pacific Basin Conference on Hazardous Waste, Edmonton, Alberta, Canada, May 7-12.

Ministry of Economic Affairs (MOEA), (1995), Industrial Waste Minimization in Taiwan, R.O.C., Taipei, Taiwan, April.

Phantumvanit, D., and de Mesa, R.C., (1995), Thailand Environment Institute, Bangkok, Thailand, personal communication with Shen-yann Chiu, East-West Center, Honolulu, Hawaii, May.

Thailand Development Research Institute (TDRI), (1986), Clean Technologies for the Pulp and Paper Industry, The Textile Industry, and Metal Coating and Finishing In Thailand, report submitted to United Nation Environment Programme (UNEP), Industry and Environment Office, Paris, France.

US Agency for International Development (USAID), (1991), Industrial Environmental Management Project (492-0465), Project Paper, Philippine Missions, Manila, the Philippines, September. 